\title{
Gênero midiático, performance e corpos em trânsito: uma análise sobre dissidências da conversação televisiva em canais no YouTube
}

\author{
Juliana Freire Gutmann \\ https://orcid.org/0000-0002-4760-670X \\ Edinaldo Mota Junior' \\ https://orcid.org/0000-0002-4022-6106 \\ Fernanda Mauricio da Silva" \\ https://orcid.org/0000-0003-3661-6475 \\ I - UFBA \\ Salvador (BA), Brasil \\ II - UFMG \\ Belo Horizonte (MG), Brasil
}

Resumo: O artigo de cunho analítico propõe reflexão sobre transformações da conversação televisiva operadas no YouTube, com especial interesse em corpos que se posicionam como dissidentes. Toma como objeto empírico três canais - Põe na Roda, Canal das Bee e Dragse - que tensionam convenções midiáticas de masculinidades e feminilidades na relação com matrizes do talk show e de programas de debate. O estudo aponta lugares de reforço da convenção binária que marca os corpos televisivos, apesar do interesse em identificar lugares de trânsito do YouTube. Apresenta abordagem historicizada do fenômeno, investindo na noção de gênero televisivo como figura de historicidades, em associação ao sentido de performance e relatos de si.

Palavras-chave: gênero televisivo; performance; YouTube.

Abstract: Media genre, performance and bodies in transit: an analysis of talk TV dissent on YouTube - This analytical paper proposes reflection on transformations of the television conversation operated on YouTube, with special interest in bodies that position themselves as dissidents. It takes as its empirical object three channels - Põe na Roda [Talk to All], Canal das Bee [Bee 
Channel] and Drag-se [Drag yourself] - that stress mediatic conventions of masculinities and femininities in relation to matrices of talk show and debate programs. The study points to places of reinforcement of the binary convention that marks the television bodies, despite the interest in identifying YouTube traffic places. It presents a historicized approach to the phenomenon, investing in the notion of television genre as a figure of historicities, in association with the sense of performance and self-reports.

Keywords: television genre; performance; YouTube.

Reconhecemos que a televisão, pensada como tecnologia e forma cultural (WILLIAMS, 1979), constitui convenções midiáticas e também nos faz ver, em movimentos mais turvos, lugares de disputa dessas convenções. Esses movimentos atingem novas proporções nas redes sociais digitais, complexa teia de discursos em que disputas se tornam a própria condição de existência material de corpos outros. Fora da TV, mas por meio de um modus operandi que nos remete a ela, a lógica dominante se vale de visibilidades assentadas essencialmente em narrativas autobiográficas. Neste trabalho, interessa-nos observar as disputas por convenções de gêneros televisivos e performances midiáticas operadas por sujeitos de dissidências sexuais e de gênero e suas reconfigurações na conversação televisiva no YouTube.

As experiências com o audiovisual em transformação, no âmbito da cultura digital, nos convocam distintas relações temporais, o que significa perceber como as experiências de identidades dissidentes sobrevivem entre regimes de visibilidades e silenciamentos, mobilizam e constroem comunidades de sentido, reorganizam e remediam experiências culturais distintas. No contexto brasileiro, chama-nos atenção, nos últimos cinco anos, a popularização de uma série de canais disponibilizados no YouTube que são feitos por sujeitos que se reconhecem em identidades LGBTQ. Esses canais abordam temas relacionados às dissidências sexuais e de gênero a partir do relato das experiências vividas pelos próprios usuários, que interpelam diretamente a audiência pela linguagem audiovisual marcadamente amadora (HORAK, 2014, p. 576).

Propomos aqui um movimento que extrapole os limites do televisivo para além do próprio suporte e busque compreender como a cultura televisiva, marcada pelo sentido de intimidade, encontra nas redes sociais digitais espaço de desenvolvimento de estratégias de conversação e constituição de subjetividades. São tomados como objeto empírico os canais brasileiros do YouTube Põe na Roda, Canal das Bee e Drag-se, cujas produções de entretenimento e informação tematizam, de diferentes formas e com diversas nuances, questões referentes a identidades dissidentes (neste caso, em relação a identidades de gêneros e sexualidades) e indicam reiterações e ressignificações do audiovisual e de certas matrizes televisivas. Buscamos, por meio dos relatos de si, de corpos e das performances acionados no canal, compreender as continuidades e possíveis rupturas de matrizes televisivas, e sua incidência na construção dessas identidades. 
Reconhecemos o YouTube como lugar de trânsito de corpos que se autodifundem por operações ordinárias, articulam e ressignificam marcas de distintas temporalidades, o que demanda ao analista esforço de historicização (GUTMANN; CALDAS, 2018). Os discursos e materialidades que atravessam as ambiências digitais constituem vetores centrais para o debate sobre mutações que atravessam a comunicação e a cultura contemporânea. Neste artigo, acionamos, a partir de Goulart, Gomes e Leal (2017), a noção de gênero televisivo/ midiático como figura de historicidades, ou seja, lugar de articulação conceitual que deixa ver, nos objetos empíricos, movimentos do tempo. Nesses termos, propomos uma análise historicizada dos corpos em atuação nesses canais no YouTube, amparados na noção de performance como conceito teórico-metodológico do audiovisual digital (GUTMANN, 2018) e do corpo midiatizado como dispositivo de reflexão sobre masculinidades, feminilidades e seus trânsitos.

\section{Gênero televisivo, performance e performatização de identidades}

Pensar relações entre corpos midiáticos e matrizes televisivas que tensionam, nas ambiências digitais, convenções do televisivo e de suas representações de masculinidades e feminilidades, implica, para nós, um movimento analítico que dê conta da forma audiovisual do YouTube como processo. Processo, nos termos de Williams (1979, p. 91), refere-se não ao entendimento daquilo que é da ordem das estruturas, mas aos modos como os atos sociais são constituídos na cultura, com "pressões exercidas por formações novas, com as suas intenções e exigências ainda não percebidas". A convocação de Williams é para que o analista considere as diversas temporalidades sociais em qualquer análise da cultura, estando atento ao senso de movimento do tempo. Nesses termos, tomamos a noção de gênero como figura de historicidade, pois "atua como uma espécie de lugar de articulação entre diversos produtos midiáticos e práticas sociais que ganha centralidade quando se busca interpretar os processos comunicativos" (GOULART; GOMES; LEAL, 2017, p. 52).

No que se refere ao gênero televisivo, convocamos uma compreensão mais ampla, não como referência classificatória dos produtos, mas como dimensão analítica de linguagens e fluxos da cultura midiática, que operacionaliza a análise de estratégias comunicativas e culturais (GOMES, 2011, p. 121). Inspirado em Foucault, Mittell (2001, p. 7) compreende os gêneros como categoria cultural, uma espiral de elementos textuais e contextuais, de práticas discursivas ativas. Ou seja, convenções de gênero emergem de relações intertextuais entre textos múltiplos, operam por meio dos domínios textuais, domínios culturais, das indústrias midiáticas, audiências, política, crítica e contextos e tempos históricos.

Por essa acepção de gênero, recorremos, a partir de Cardoso Filho e Gutmann (2018), à hipótese de que os gêneros materializam determinados padrões de gosto e 
de sensibilidade, os quais norteiam configurações de performances. Assim, de modo articulado, gênero midiático e performance podem auxiliar a análise comunicacional de convenções e de suas ressignificações na cultura; do jogo proposto e aceito entre os sujeitos comunicativos, que nos faz reconhecer desestabilizações e estabilizações de convenções e regulações.

Vistas como formas em ação (SCHECHNER, 2006, p. 20), as performances se entrecruzam, conectam-se e constituem fluxos midiáticos, de sentidos, de identidades e tempos históricos. Os canais Põe na Roda, Canal das Bee e Drag-se são espaços cujas condições materiais e simbólicas constituem uma determinada cultura e nos fazem ver, no marco das performances, tensionamentos de gêneros televisivos, de identidades e suas continuidades, rupturas, hegemonias e contra-hegemonias simbólicas atuantes.

Schechner (2006) reconhece que eventos, ações e comportamentos podem ser examinados "como" performance justamente porque estão em processo. Expressam-se por meio de ações que envolvem repetições, mas que, por ser forma em ação, se alteram, alternam e recombinam modos de agir. Seriam as disrupções dessas reiterações que constituiriam, pela performance, mudanças. Isso nos permite dizer que as singularidades (pensadas aqui como fricções/rupturas) da performance nas ambiências aqui estudadas resultam de associações materiais variadas do corpo - gestualidade, tom e ritmo de voz e de movimentos corporais, iluminação, enquadramentos, montagem, som etc. - com seus contextos de interação, também constituídos por materialidades relacionadas ao corpo que age, aos dispositivos técnicos, aos tempos de fala etc.

Esses regimes de visibilidade orquestrados no âmbito das redes sociais digitais, antes de meras expressões narcísicas, são vistos por Simone Sá e Beatriz Polivanov (2012) como modos de performatização de identidades. O conceito de autoreflexividade proposto por Anthony Giddens é apropriado pelas autoras como mecanismo de construção das "narrativas de si", em que o valor de autenticidade é convocado pelo sentido de "história partilhada" (ibidem, p. 581), continuamente construído e negociado entre os atores comunicativos. Em Foucault (1992), a narrativa de si é um ato de constituição dos sujeitos, de subjetivação dos discursos que ocorre diante uns dos outros como uma das práticas de cuidado de si. Narrar-se diante dos outros é um movimento de interiorização que encontra na rememoração do passado ou no cotidiano um espaço para a construção de si.

Para Sá e Polivanov (2012), esse processo de performatização de identidades, esgarçado nas e pelas redes sociais, em que as narrativas de si são construídas e disputadas como valor, dá-se "em tensão, sujeito a ruídos, uma vez que sempre atravessado pela relação com os outros atores da rede sociotécnica na qual o usuário se insere (SÁ; POLIVANOV, 2012a, p. 581). Põe na Roda, Drag-se e Canal das Bee, como formas expressivas contemporâneas, abrem-se como espaço para construção dessas narrativas, partilhadas e disputadas entre agentes e espectadores/seguidores. 


\section{Matrizes televisivas e corpos midiáticos em trânsito no YouTube}

Em estudo realizado por Gutmann e Silva (2017), as autoras demonstram como talk shows brasileiros se definem em duas matrizes com convenções próprias, porém tensionadas, sobre masculino/feminino a partir da constituição histórica de corpos midiáticos (de apresentadores, participantes, audiência). As autoras compreendem que a formação cultural do talk show tem, entre suas convenções, a constituição de corpos midiáticos que ratificam padrões binários (homem/mulher). Ainda que não tenha sido objeto central de pesquisa, Gutmann e Silva atestam que a compreensão das historicidades do gênero televisivo, suas convenções discursivas e materiais, também se relaciona, historicamente, a corpos midiáticos.

Conforme Gutmann e Silva (ibidem), a linhagem que teria o programa Jô Soares Onze e Meia (SBT, 1988-1999) como matriz reforça o masculino pelo sentido de autoridade, intelectualidade e polidez. No programa Gordo a Gogo (MTV, 2000-2005), o masculino é ressignificado pelo sentido de virilidade. Já no contemporâneo The Noite (SBT, 2014 - em atuação), a figura do apresentador se sustenta num machismo declarado e na representação do feminino como "mulher objeto". A segunda linhagem, analisada desde Hebe (SBT, 19862010) até o Encontro com Fátima Bernardes (Rede Globo, 2012- em atuação), ressignifica matrizes televisivas populares e o lugar do ordinário, das histórias de vida, o caráter emocional e íntimo dos relatos. O feminino ganha corpo da mulher "dona de casa", "mãe de família", delicada e sensível. Como estratégia de autoridade, também aparece o corpo da jornalista que desempenha o papel de conselheira, conciliadora dos dramas sociais.

Inspirados nesse movimento, partimos para a investigação dos canais Põe na Roda, Canal das Bee e Drag-se buscando interpretar, pela análise dos corpos, convenções e ressignificações relacionadas a gêneros midiáticos, pistas que indiquem continuidades e descontinuidades do televisivo e suas relações com masculinidades, feminilidades e seus trânsitos na ambiência digital.

São várias as definições que circulam pela web sobre o canal brasileiro Põe na Roda": "canal gay de humor", "canal de notícias LGBT", "variedades do universo gay", "de informação LGBT". Esta última definição endossa o lugar da entrevista como estratégia de legitimação de um posto "autorizado" que se quer constituir, na relação com o jornalismo e a informação. Dentre os espaços que evocam esse tipo de legitimação, destacamos dois quadros: Saindo do Armário e Sauna Justa.

1 O Põe na Roda surgiu em abril de 2014 com a proposta de ser um canal de humor "voltado para os gays, [...] que pouco se veem representados na mídia" (CAPARICA, 2014). O projeto foi idealizado pelo jornalista Pedro HMC, que integrou a equipe de redação dos programas Furo e Comédia MTV, colaborou com Dani Calabresa no CQC e nos programas Fritada e Vamos Rachar, do Multishow. Ao longo de 4 anos no ar, Põe na Roda recebeu o prêmio Digital 2016, do Instituto Sou+Jovem, na categoria melhores do ano, o prêmio Digital Awards 2017, na categoria Melhor Canal de Comportamento, e seu idealizador, Pedro HMC, lançou o livro Um livro para ser entendido, em 2016, em que relata as experiências na produção dos conteúdos de temática LGBT. O canal, até a presente análise, possui 897 mil inscritos, 361 vídeos que totalizam mais de 130 milhões de visualizações. A página do Põe na Roda no YouTube está disponível em <https://www.youtube.com/user/canalpoenaroda>. Acesso em 10 out. 2018. 
No quadro Saindo do Armário, o apresentador Pedro HMC entrevista uma personalidade LGBTQ que revela seu processo de aceitação e reconhecimento. Diferentemente dos enquadramentos televisivos de situações de conversa (que revezam os planos fechados com planos gerais dos sujeitos de fala no mesmo quadro), a conversação é configurada por dois planos que enquadram separadamente cada sujeito. Eles não olham para a câmera, o que nos coloca no lugar mais distanciado de testemunhas da conversa. O tom doméstico aparece no cenário improvisado (um painel com pinturas em grafite) e na baixa qualidade do áudio.

O corpo do apresentador é o corpo másculo do homem cis gay, que ali evoca autoridade pelo distanciamento com os entrevistados, como ocorre ao entrevistar Gloria Groove $^{2}$ " "Tem muitas trans que se descobrem trans no momento da montagem como drag, isso lhe ocorreu?". Ou quando questiona: "Você não foi aquele gay que se descobriu tarde?". Em nenhum momento ele se coloca como "nós" do discurso. Pedro também recorre ao celular durante toda a entrevista, como símbolo de reforço ao sentido de apuração. Nos comentários do canal, onde é possível observar expansões dessa conversação, os seguidores endossam esse lugar da autoridade tradicionalmente relacionada a práticas jornalísticas. Um internauta afirma: "Pedro, parabéns por seu estudo antes de entrevistar. Você está incrível"; outro reforça: "Tu arrazou! adorei esse formato... ficou muito entrevista do Fantástico. MUITAS PALMAS!! ${ }^{\prime \prime}$

No quadro Sauna Justa ${ }^{4}$, uma paródia do programa de debate Saia Justa da GNT, o ambiente sexualizado das saunas gays transforma-se em espaço para o debate. É possível observar uma hegemonia do falo nesse ambiente de conversação pela configuração do corpo gay associado ao desejo sexual exacerbado. No episódio intitulado Gays x Lésbicas, Pedro HMC diz: "Mulher é sensível, e o homem mais carnal. A gente vive na sauna, [...] convivemos com vários pintos no celular". Quando entrevista Paulo Vaz, homem trans, confessa: "Nós gays realmente falamos muito de pinto". Essas pistas nos indicam uma associação do desejo restrito ao fator biológico e reforçam, na conversação, uma matriz heterossexual.

Chamamos aqui hegemonia do falo a força dominadora do corpo masculino cisgênero e a representação que o órgão genital masculino adquire historicamente como instrumento de poder. Butler (2003) toma a ideia de uma hegemonia falocêntrica a partir do estabelecimento de papéis masculino ou feminino tidos como universais, aos quais se atribui coerência e continuidade com a repetição dos papéis possíveis entre homens e mulheres.

2 Episódio disponível em < https://goo.gl/7au4Ug>. Acesso em 23 jan. 2019.

3 Comentário de autoria do perfil Rafael Vidor, disponível na exibição do vídeo no canal do YouTube. Acesso em 23 jan. 2019.

4 Episódio disponível em <https://goo.gl/DrjGTZ>. Acesso em 23 jan. 2019. 


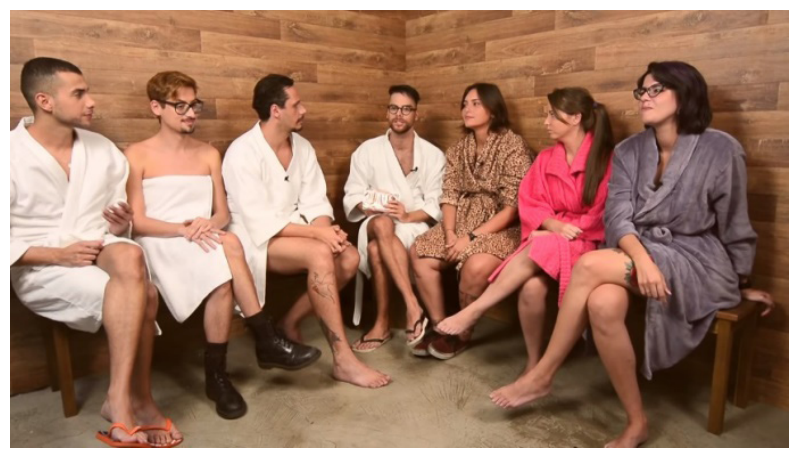

Fig. 1. Imagem capturada do episódio Gays x Lésbicas, do quadro Sauna Justa

No canal, o lugar de visibilidade do corpo é o da naturalização de comportamentos e práticas sociais de uma subcultura gay, branca e cisgênero. Destaca-se a apropriação dessa matriz heterossexual para construção de outras masculinidades possíveis, a partir da própria construção corporal. Das distintas nuances das identidades gay, o corpo construído em Põe na Roda nos convoca relações históricas em torno das barbies, no contexto americano, como uma espécie de resposta aos sentidos de ser bicha/afeminada/feminilizada (queer ou faggy, na língua inglesa), por meio da construção corporal. As barbies exploram os aspectos masculinizados em corpos musculosos, uma estética higienizada, saudável, em busca de naturalização e aceitação por meio de padrões corporais e exploração desses corpos saudáveis nas boates, clubes e discotecas.

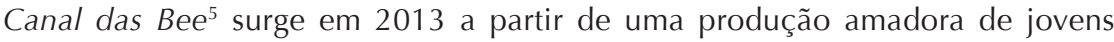
universitários. Nele, vemos referências a um "canal de autoconhecimento", ou "canal de ativismo LGBT". Além dos conteúdos comportamentais, o grupo promove ações sociais, como "Rolezinho LGBT" e o projeto "Ajude as Bee". Os mecanismos de interação e configuração de intimidade se dão pela troca de experiências por parte das mediadoras/ youtubers, que relatam suas vivências pessoais sobre "ser lésbica", dos entrevistados (outros youtubers ou personalidades conhecidas na internet) e pela própria interação do espectador/seguidor na seção de comentários.

O grupo, composto pelos youtubers Jessica Tauane, Fernanda Soares, Debora Baldin e Hebert Castro, busca promover diversidade nos modos de inserção dos corpos projetados no canal, colocando em igualdade as experiências do homem cis gay e da mulher cis lésbica. Os relatos de si são enquadrados como "inspiração", "apoio psicológico",

5 Segundo a descrição na plataforma YouTube, Canal das Bee é "um canal contra o preconceito, contra a transfobia, a bifobia, a lesbofobia, o machismo. Um canal a favor da diversão, do riso e de viver a vida do jeito que você quiser". Lançado a partir do trabalho de conclusão de curso em Comunicação pela PUC-SP, idealizado por Jéssica Tauane, o canal, em menos de um ano de lançado, obteve mais de 160 mil acessos no YouTube. Conquistou, em 2013, o prêmio Content Talent Show do youPIX Festival, na categoria YouTube. Atualmente, possui 359 mil inscritos, 593 vídeos publicados, que somam mais de 31 milhões de visualizações. O canal pode ser acessado em <https://www.youtube.com/user/CanalDasBee>. Acesso em 12 out. 2018. 
"empoderamento". Assim como as cartas no rádio, as ligações telefônicas em programas de TV, o Canal das Bee posiciona os corpos dos mediadores em contato direto com sua audiência e convoca o espectador para uma relação olho-no-olho.

É forte a intenção de mobilizar outros corpos para mudança de atitudes e comportamentos. No quadro Pergunte às Bee $\# 98^{6}$, com a presença da youtuber Jout Jout Prazer, Jéssica Tauane convoca as mulheres gordas a ocuparem os espaços: "Se libertem dessas amarras opressoras que vocês têm com seu corpo, e vão à praia. [...] Ninguém tem nada a ver com suas gorduras, só você mesma. Você é linda". A estratégia discursiva dos relatos de si, geralmente, termina com "o que eu aprendi com essa experiência foi...", reforçando o desejo do canal de promover mudança.

No Canal das Bee, o relato das experiências vividas se aproxima das narrativas do vlog típicas das ambiências digitais, convocando o internauta para a partilha de experiências. No Pergunte às Bee \#109, com tema sobre masturbação feminina ${ }^{7}$, Jéssica Tauane e Débora Baldin falam como "nós", dando relevo ao sentido de comunidade: "A gente é doutrinada a ter muito pudor com nossa vagina, e os meninos cis já é diferente, eles já podem brincar de estimular"; "Aponta o dedo pra amiguinha que diz que tem nojo e fala 'você tá errada, você tem nojo de si própria'". Enquanto fala, projeta seu corpo para frente, apontando o dedo para a câmera e gesticula, reagindo aos comentários. É enfático o vínculo com a sexualidade como mecanismo de produção de suas próprias corporalidades. O corpo midiático autorizado ali é, nessa perspectiva, o corpo da "mulher livre" afirmado como sinônimo de dissidência do padrão de beleza hegemônico da figura feminina.
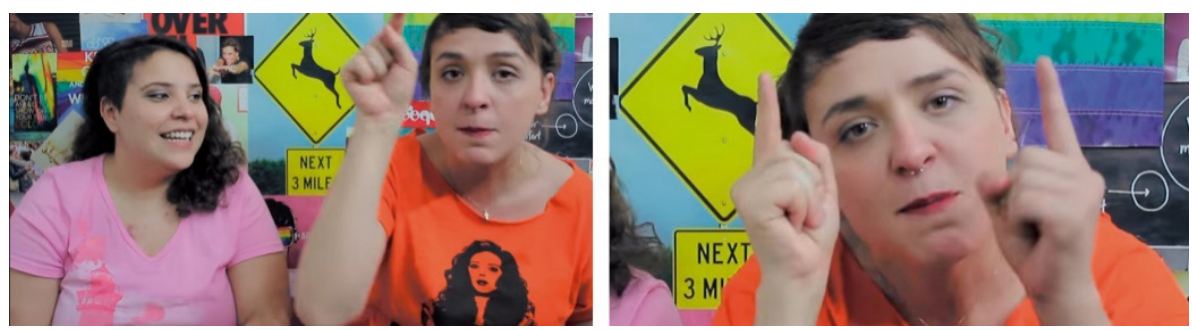

Fig. 2. Imagens capturadas do episódio Pergunte às Bee \#109

O Drag-se $e^{8}$ é um canal voltado para a cultura drag composto por uma série de programas inspirados em convenções de gênero televisivo (reality shows, talk shows,

6 Episódio disponível em <https://goo.gl/wGaVQQ>. Acesso em 23 jan. 2019.

7 Episódio disponível em <https://goo.gl/UZKsJv>. Acesso em 23 jan. 2019.

8 O Drag-se surgiu em 2014, inicialmente, como uma websérie para o YouTube, que propunha acompanhar a vida de treze artistas da nova geração de drags cariocas. Com financiamento da Riofilme e de doações por meio do Catarse, a série aborda a criação de personagens artísticos e como esse processo afeta o cotidiano dos jovens, ao mesmo tempo que traz à tona o debate sobre a diversidade aos sujeitos. Em 2015, o elenco do Drag-se desfilou no lançamento da coleção do estilista paulista Fernando Cozendey. Agora como canal, Drag-se possui mais de 62 mil inscritos, 443 vídeos e cerca de 6 milhões de visualizações em seus conteúdos veiculados. O canal está disponível em <https://www.youtube.com/user/dragsetv>. Acesso em 12 out. 2018. 
coberturas, séries televisivas etc.). Os corpos drag queens e drag kings ${ }^{9}$ do canal são lugares de constituições de subjetividades e fricções ligadas à cultura drag. Mesmo montadas, as drags reforçam, no corpo, marcas de masculinidades que desestabilizam até mesmo o que é ser drag. Há ali diversos níveis de trânsitos entre formatos televisivos, formas do youtuber, feminilidades, masculinidades, transexualidades, binarismos etc.

Em relação ao corpo dos mediadores, nos concentramos nas drags Betina Polaroid, no programa Drag Photo Studio ${ }^{10}$, e Pandora Yume, no programa Pandora entra na sala ${ }^{11}$. O Drag Photo Studio constitui-se a partir da conversação entre a drag fotógrafa Betina Polaroid e uma convidada. O corpo é lugar de constituições de subjetividades ligadas ao universo drag, muitas vezes reforçado por inspirações da infância (boneca Barbie, Mulher Gato, Carmem Sandiego), o que acentua o discurso autobiográfico (da apresentadora e de sua entrevistada). Betina é, ao mesmo tempo, mediadora, drag e fotógrafa.
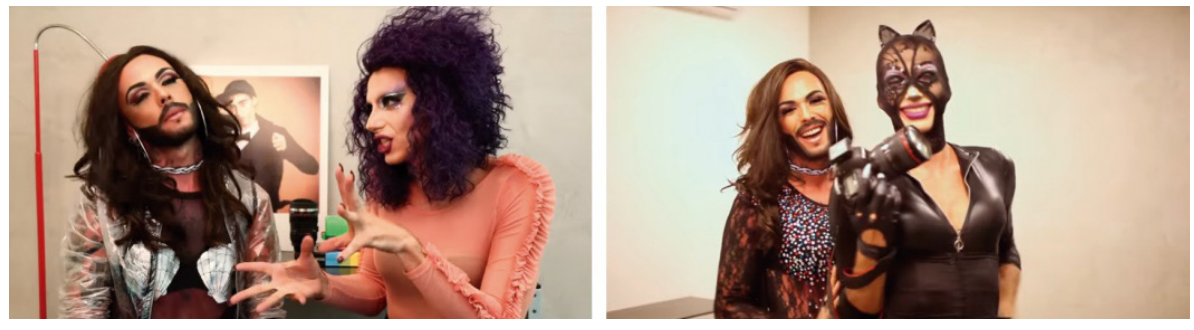

Fig. 3. Betina Polaroid entrevista e fotógrafa Taty, do perfil Bixa Melhore.

Imagens capturadas do programa Drag Photo Studio

É possível fisgar aí convenções do televisivo reelaboradas por formas expressivas do YouTube: chamada, vinheta do programa, o lugar de intimidade. A questão das personalidades celebrizadas, que justifica a relevância da entrevistada, é central. O que valida a presença da entrevistada é sua circulação na cultura drag, especialmente pela entrada no YouTube. As cenas transitam por espaços da casa: o quarto, a sala, o banheiro e o ato de montar-se fazem parte da lógica do episódio. Ao mesmo tempo, a cultura do meme é explorada na montagem, o que evoca esse sentido de bricolagem e trânsito de imagens. Quando a entrevistada Tati' ${ }^{12}$, do canal Bixa Melhore, diz: sou "pisciano com ascendente em gêmeos", aparece a imagem intensamente mimetizada da personagem Nazaré Tedesco, ali agora re-memetizada com a inserção de símbolos da astrologia.

9 Drag queens são, geralmente, homens cisgêneros que constroem uma performance artística a partir de elementos feminilizados. Drag kings é o movimento de expressão artística em que pessoas, em sua maioria mulheres cisgênero, constroem suas marcas corporais e performances a partir de elementos visuais de homens cisgênero.

10 Uma playlist criada pelo canal Drag-se reúne 16 vídeos do programa Drag Photo Studio. Todos os vídeos podem ser visto na plataforma no link disponível em <https://goo.gl/FjUKnb>. Acesso em 23 jan. 2019.

11 O programa Pandora entra na sala não está disponível em uma playlist, mas todos os vídeos feitos para o programa podem ser vistos através do campo de busca do próprio canal. Os vídeos estão disponíveis em <https://goo.gl/ tmTnDs>. Acesso em 23 jan. 2019.

12 Episódio disponível em <https://goo.gl/3UcrW4>. Acesso em 23 jan. 2019. 
No programa Pandora entra na Sala, a construção de um corpo drag se apropria da experiência de consumo midiático de Pandora a partir de referências explícitas aos programas da MTV Brasil. As vestimentas são compostas por meia-arrastão com saias curtas e camisetas pretas de bandas de rock ou quimonos japoneses junto a argolas penduradas ao pescoço e botas de couro. A barba e o alargador na orelha se misturam aos gestos que brincam com marcas feminilizadas - ela mexe nos cabelos e olha as unhas enquanto ouve as perguntas.

A referência a Penélope Nova, que foi VJ da MTV e apresentou o programa Ponto $P \hat{e}^{13}$, aparece no corpo disposto para a conversa íntima sobre sexo, que dá um tom bastante juvenil ao programa. Sobre o sofá, Pandora brinca com os problemas expostos pelos espectadores. No episódio Ponto Pandora ft Onírica ${ }^{14}$, quando a internauta diz que viveu uma relação perfeita, Pandora debocha desse ideal de perfeição, diz que "depois que oficializa o namoro é só ladeira abaixo"; ou quando minimiza uma situação, após ler o relato de um internauta: "Cadê o problema aqui, gente? Vai ser feliz!". Esse tom bemhumorado reforça outra forma de estabelecer intimidade, marcada pelo estreitamento dos laços entre os participantes da conversa.
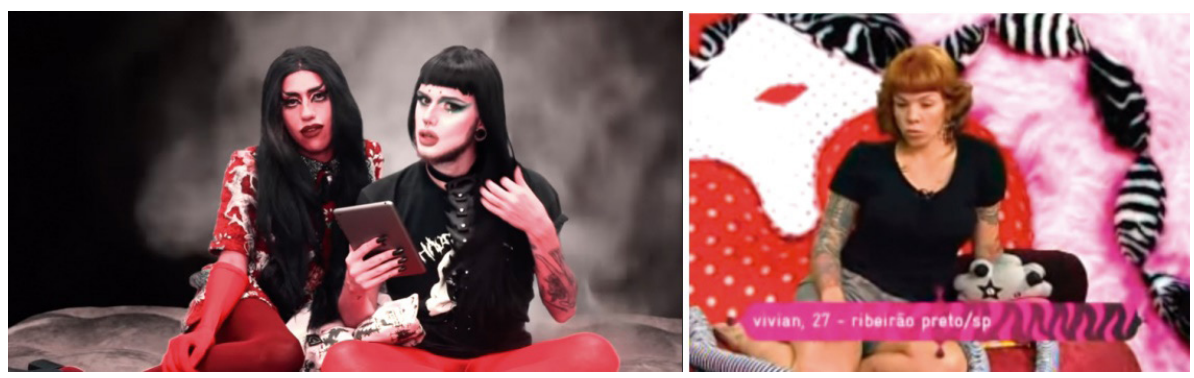

Fig. 4 e 5. Imagem capturada do Ponto Pandora, do canal Drag-se, ao lado, imagem capturada do programa Ponto Pê, exibido pela MTV Brasil.

O Drag-se nos faz ver lugares de disputa no que diz respeito à identidade desses corpos. Muitas das entrevistadoras exploram no corpo, marcas de masculinidades: músculos, cabelo debaixo do braço, barba. Há também entrevistadas mulheres cis, que se mostram no corpo drag. Há drags que se definem por "ela", outros por "ele". No Photo Studio, o momento de transformação (quando entrevistada e entrevistadora aparecem num banheiro doméstico juntas) reforça essas "ambiguidades" nos corpos. Assim, parece-nos possível identificar aqui um lugar de trânsito do corpo e de marcas de gênero no programa de entrevista, diluindo fronteiras entre público e privado, pessoal e político.

\footnotetext{
13 Programa exibido pela MTV Brasil, apresentado por Penélope Nova entre 2004 e 2007. Os telespectadores participavam através de ligações telefônicas e partilhavam questões sobre sexualidade com a apresentadora.

14 Episódio disponível em <https://goo.gl/7VtQZQ>. Acesso em 23 jan. 2019.
} 
Pelo exposto, reconhecemos em Põe na Roda, Canal das Bee e Drag-se lógicas de funcionamento de uma hegemonia de matriz heterossexual, que regulam e ao mesmo tempo disputam forças em contextos distintos. Obviamente este não é um fenômeno "do YouTube". "Representações divergentes, alternativas, contraditórias" atravessam as redes sociais digitais e a televisão (LOURO, 2000, p. 18) num movimento permanente de mediação e remediação cultural, o que nos faz reconhecer a dimensão processual da cultura contemporânea em transições continuadas (GOULART; GOMES; LEAL, 2017).

A convocação para as distintas temporalidades sociais, proposta por Williams (1979), nos permite pensar como esses canais, como produtos subculturais, produzem temporalidades alternativas dentro da própria lógica capitalista e heteronormativa. Nesse sentido, os sujeitos LGBTQ criam possibilidade de existência fora de marcadores que enquadram suas experiências de vida em padrões de nascimento, casamento, reprodução/ sexualidade e morte. Halberstam (2005) reconhece que essa temporalidade queer, que disputa uma emergência, permite repensarmos práticas sociais em disputa, suas "hierarquias e dinâmicas de poder, e a tendência a resistir ou render-se" (HALBERSTAM, 2005, p. 6).

A visibilidade que as performances acionam, marcada por continuidades e descontinuidades, deve ser vista não como uma solução para silenciamentos históricos, conforme Dinshaw et al (2007, p. 197), e sim como uma variante dos processos de invisibilidade, como "efeitos históricos de uma rede contraditória entre masculinidade, feminilidade, heterossexualidade e homossexualidade", que seria intrinseca ao sistema moderno de sexo/gênero, mas que encontra no relato de suas próprias experiências uma inscrição no tempo. Por isso, esses regimes de visibilidade, tão contraditórios e complexos, se articulam e disputam sentidos a partir de uma lógica que ressignifica corpos em redes de sociabilidades como forma de resistência (ou de existência).

\section{Consideração final (ou projeção para uma investigação futura)}

Tomado como figura de historicidades, o gênero televisivo nos fez ver lugares de transitoriedades, de continuidades e ressignificações da conversação televisiva (ou melhor, da conversação televisiva em transformação no YouTube). De um corpo que materializa convenções de gênero midiático e de suas representações de feminilidades, masculinidades e seus trânsitos. Nesse sentido, o estudo empírico aqui apresentado aponta para continuidades desse corpo que constitui matrizes do talk show brasileiro, como demonstraram Silva e Gutmann (2017), na relação com feminilidades e masculinidades, mas também movimentos descontínuos, pontos de ruptura que indicam transformações no gênero, no audiovisual, na conversação, no corpo midiático que circula nas redes sociais digitais.

Nos canais aqui analisados, pudemos reconhecer alguns lugares de desestabilizações a partir da própria lógica de um sistema que silencia inteligibilidade aos seus corpos. Em alguma medida, os canais experimentam expandir "perguntas, fantasias, dúvidas e 
a experimentação do prazer" (LOURO, 2000, p. 18) do plano do segredo e do privado, para um privado que deixa ver sua dimensão social e política, quando ganha veiculação pública a partir do YouTube.

Tendo em vista os elementos que configuram a cultura digital e a crescente criação de perfis e canais especializados LGBTQ, do ponto de vista dos corpos e da performance, observamos que é pelo reconhecimento do próprio interlocutor que se cria uma "energia" de mediação (interações, discussões, apoio às causas identitárias, partilha, engajamento). Esta energia tem o corpo e a performance como dimensão de existência. Como paisagens afetivas (GROSSBERG, 2012), os corpos dos sujeitos estão engajados e materializam-se politicamente, reafirmando possibilidades outras de expressão de identidades.

Como possibilidade futura de investigação, esta análise aponta para a potência da noção de identidade de gênero, também, como dimensão conceitual de acesso, pelos objetos empíricos, a movimentos do tempo. Nessa direção, indicamos como pista para posterior investigação a abordagem das identidades de gênero constituídas midiaticamente como lugares teórico-metodológicos de análise de transformações culturais e midiáticas, reforçando o argumento de que constituições históricas não são construções de consenso mas dimensões de disputas.

Juliana Freire Gutmann é professora adjunta do Departamento de Comunicação e do Programa de PósGraduação em Comunicação e Cultura Contemporâneas da UFBA e doutora em Comunicação e Cultura pela mesma universidade.

jugutmann@gmail.com

Edinaldo Mota Junior é doutorando do Programa de PósGraduação em Comunicação e Cultura Contemporâneas pela UFBA.

eamotajr@gmail.com

Fernanda Mauricio da Silva é professora adjunta do Departamento de Comunicação Social e do Programa de Pós-Graduação em Comunicação da UFMG . Doutora em Comunicação e Cultura pela UFBA.

fernandamauricio@gmail.com 


\section{Referências}

BUTLER, J. Problemas de gênero: feminismo e subversão de identidade. Trad. Renato Aguiar. 1 ed. Rio de Janeiro: Ed. Civilização Brasileira, 2003.

CARDOSO FILHO, J.; GUTMANN, J. F. Performances como expressões da experiência estética: modos de apreensão e mecanismos operativos. (no prelo, 2018). Porto Alegre: Intexto.

DINSHAW, C. et al. Theorizing queer temporalities: a roundtable discussion. GLQ: A Journal of Lesbian and Gay Studies, Durhman, Duke University Press, vol. 13, n. 2-3, p. 177-195, 2007.

FOUCAULT, M. A arqueologia do saber. Trad. Luiz Felipe Baeta Neves. Rio de Janeiro: Forense Universitária, 2010.

FOUCAULT, M. A escrita de si. In: O que é um autor? Lisboa: Passagens. 1992. pp. 129-160.

GOMES, I. M. M. Gênero televisivo como categoria cultural: um lugar no centro do mapa das mediações de Jesús Martín-Barbero. FAMECOS. Porto Alegre, v. 18, n. 01, janeiro/ abril 2011.

GOULART, A. P.; LEAL, B.; GOMES, I. A historicidade dos processos comunicacionais: elementos para uma abordagem. In: MUSSE, C. F.; VARGAS, H.; NICOLAU, M. (Orgs.). Comunicação, mídias e temporalidades. Salvador/Brasília: EDUFBA/COMPÓS, 2017.

GROSSBERG, L. Cultural Studies in the future tense. Durham/London: Duke University Press, 2012.

GUTMANN, J. F.; CALDAS, F. É TV na Internet? Matrizes midiáticas e definições em disputa do YouTube no Brasil. Anais do XXVII COMPÓS. Belo Horizonte: PUC-Minas, 2018.

GUTMANN, J. F.; SILVA, F. M. Matrizes e matizes do talk show no Brasil. In: FRANÇA, V.; GOMES, I. M. M.; COHEN, E. Gêneros midiáticos e identidades. Belo Horizonte: PPGCOM UFMG, 2017, p. 47-66.

HALBERSTAM, J. Queer temporality and postmodern geographies. In: HALBERSTAM, J. In a queer time and place: transgender bodies, subcultural lives. New York/London: New York University Press, 2005, p. 1-23.

HORAK, L. Trans on YouTube: intimacy, visibility, temporality. TSQ: Transgender Studies Quarterly, Durham, vol. 1, n. 4, p. 572-585, nov. 2014.

LOURO, G. L. Pedagogia da sexualidade. In: LOURO, G. L. O corpo educado: Pedagogias da sexualidade. Belo Horizonte: Autêntica, 2000.

MITTELL, J. A cultural approach to television genre. Cinema Journal, vol. 40, nº 3, Spring, 2001.

SÁ, S.M. A. P.; POLIVANOV, B. B. Auto-reflexividade, coerência expressiva e performance como categorias para análise dos sites de redes sociais. Contemporânea, Salvador, v. 10, p. 574-596, 2012.

SCHECHNER, R. Performance Studies: an introduction. New York: Routledge, 2006.

WILLIAMS, R. Marxismo e Literatura. Trad. Waltensir Dutra. Rio de Janeiro: Jorge Zahar, 1979.

Artigo recebido em 30/01/2019

e aprovado em 03/05/2019. 